\title{
A history of health technology assessment at the European level
}

\author{
David Banta \\ Professor Emeritus, University of Maastricht
}

Finn Børlum Kristensen

DACEHTA, National Board of Health

\author{
Egon Jonsson \\ University of Alberta and University of Calgary and Institute of Health Economics
}

This study summarizes the experience with health technology assessment (HTA) at the European level. Geographically, Europe includes approximately fifty countries with a total of approximately 730 million people. Politically, twenty-seven of these countries (500 million people) have come together in the European Union. The executive branch of the European Union is named the European Commission, which supports several activities, including research, all over Europe and in many other parts of the world. The European Commission has promoted HTA by several policy positions and has funded a series of projects aimed at strengthening HTA in Europe. Around fifteen of the European countries now have formal national programs on HTA and some also have regional public programs. All countries that are members of the European Union and do not have a national approach to HTA have an interest in becoming more involved. The HTA projects sponsored by the European Commission have focused on networking and collaboration among established agencies and institutions for HTA, however, also on capacity building, support, and facilitation in creating mechanisms for HTA in European countries that still do not have any program in the field.

Keywords: Health technology assessment, History, Health planning, Europe

Health technology assessment (HTA) in Europe essentially began in the 1970 s with both formal and informal initiatives in different countries. Sweden initiated a program on evaluation of medical technology at that time, and several countries such as the United Kingdom, France, and the Netherlands were already increasingly using what was generally referred to as "scientific standards" in deciding what health technologies to provide. Furthermore, some countries, notably the Netherlands through the Dutch Health Council, carried out and published policy-oriented analyses that seem very much like HTAs in retrospect.

In 1979, the Swedish Planning and Rationalization Institute of the Health Services (SPRI) sponsored an international workshop on HTA in Stockholm (9). Many of those later involved in HTA at the European level took part in this seminar, including Egon Jonsson, Tore Schersten, Johannes Vang, and
David Banta. What that conference accomplished was to begin a process that has ended in a moral imperative to use best evidence in making policy, administrative, and clinical decisions in health care. Several other groups became interested in HTA at that time, including the Organization of European Medical Research Councils, which sponsored a meeting in Denmark in 1985.

In Europe, consensus conferences also played an important role in the early development of HTA. This concept, launched by the National Institutes of Health in the United States at the end of the 1970s, was quickly adopted in several countries in Europe. A large-scale program of consensus conferences was launched in Sweden in 1980, and somewhat later in many other countries throughout Europe. Consensus conferences were helpful in generating a broader interest in scientific evidence among policy makers, clinicians, and the 
general public. Thereby, indirectly, these conferences created a wider understanding of the need for comprehensive assessments in health care.

The benefits and prospects of international collaboration were recognized early by everyone involved in HTA. In 1982, plans were drawn by a joint European-United States initiative for a scientific journal on health technology assessment, and the first issue of the International Journal of Technology Assessment in Health Care was published in 1985, with Egon Jonsson and Stanley Reiser as Co-editors. At the same time, people from the United States and Europe took measures to establish the International Society on Technology Assessment in Health Care (ISTAHC), which held its first meeting at WHO in Copenhagen in 1985. Approximately sixty delegates attended that first Society meeting. The involvement of the European office of the World Health Organization (WHO), through its regional advisor on health technology assessment, Johannes Vang, was also of critical importance at this stage. ISTAHC held eighteen annual meetings (half of them in Europe and the other half in the United States) and several other international meetings up to 2003, after which the Society re-formed into Health Technology Assessment international (HTAi) in 2004.

The Dutch government was stimulated by the head of the Health Council, Els-Borst Eilers, former treasurer of ISTAHC, and later Minister of Health in the Netherlands, to appoint a Commission on future healthcare scenarios in 1985. The commission hired David Banta as chair, and the project generated a wide range of publications on the matter and further increased the interest in HTA in Europe (4).

A most important contribution toward the advancement of HTA in the individual countries of Europe was the establishment of many agencies in the field. The first national agency was established in 1987, that is, The Swedish Council on Technology Assessment in Health Care, more generally known by its acronym SBU. Shortly thereafter, several other European countries established formal agencies for health technology assessment, notably France, and Catalonia in Spain (where regional agencies now also exist in Andalusia, Basque, Valencia, Galicia, and Madrid, together with a national agency). In the 1990s, additional agencies or formal programs were established in Scotland, Denmark, Finland, Germany, Norway, Switzerland, Austria, and Hungary followed by Ireland, Belgium, Latvia, Poland, and Italy in this century. Several of the early European agencies were founding members in 1993 of the International Network of Agencies for Health Technology Assessment (INAHTA). A unique program for HTA in Europe is found in the UK National Health Service Research and Development Program. In 1999, the UK government established the National Institute for Clinical Excellence (NICE), which has a strong mandate to provide guidance for best practice based on findings from research. All agencies experience the need to account for countryspecific circumstances, such as the actual healthcare system, financing of health care, demography, disease panorama, available resources, and wealth. Most of the HTA agencies in Europe are advisory bodies and have no regulatory functions. Their organization varies to some extent, but there are more similarities than differences among the agencies. Most of the agencies select specific technologies for assessment, whereas others address all technologies used for a particular health problem (10).

The involvement of the European Commission arguably became a very important factor in promoting HTA at the European level, along with ISTAHC and INAHTA. In addition, the World Bank played a key role in this respect in some countries, especially those in Central and Eastern Europe. In 2003 WHO EURO took some initiatives for evidence in health care (3) and established the Health Evidence Network www.euro.who.int/hen

\section{THE EUROPEAN COMMISSION AND HTA}

In all of the twenty-seven countries, which make up the European Union, the State has the responsibility for providing health care and universal coverage, whether tax- or insurancebased. All of these countries face essentially the same kind of challenges for their healthcare systems: ageing populations, and complaints about waiting times, accessibility, and quality of care. A major common problem was and still is the escalating costs of health services at the same time as there is widespread public and professional demand for new healthcare technology. In trying to deal with these issues and to balance biomedical advances with the resources available, the Governments of the European countries frequently turned to the scientific community to elucidate and explain what policy options there are to approach the challenges, and to provide some evidence as a basis for decisions of what ought to be publically funded.

The European Commission supported several studies related to HTA in the early 1980s. These were mostly done under the program on health services research, and HTA was not seen strategically at that point in time, but was viewed as yet another form of health services research. However, by the mid 1980s, the Health Services Research Committee of the European Commission began to favor HTA with contracts on economic appraisal, variations in use of particular technologies, and mechanisms for regulating expensive health technologies in different countries $(8 ; 14)$.

The so-called Maastricht Treaty of the European Union included public health in the mandate of the European Commission for the first time and led to the beginning of a European public health policy. The Health Ministers of the member states identified "value for money in health care" as a priority issue for the European Commission. In 1991, the Health Ministers identified HTA as a key tool to improve the management of scarce healthcare resources, and this was further strengthened in a policy document from 2000 in which the Commission stated: "Technological developments in the 
health field will be a focus for action in the new program. The Commission intends to strengthen health technology assessment structures and mechanisms by supporting collaboration between the agencies involved to refine methodologies, promote joint working, and help disseminate the results of studies effectively" (5).

By the early 1990s, contacts between those working in HTA in different countries had become increasingly frequent and intense. Those working in national and regional programs began to talk about the need for mechanisms for coordination of HTA work at the European level, both to minimize the duplication of studies that was increasingly being seen (heart transplant, osteodensitometry) and to begin to rationalize health care in all member states of the European Union.

From 1993 to 2008, the Commission supported four major projects in HTA. These projects collectively, united the agencies in many ways, for example, in efforts to perform joint assessments, to improve HTA methodology, and effective dissemination and impact, and in general collaboration in the field.

The first in these series of formal collaboration was the EUR-ASSESS project, involving approximately 100 people from around Europe. This project ran from 1994 to 1997 and focused on (i) harmonization of HTA methodology, (ii) priority setting processes, (iii) effective strategies for disseminating results, and (iv) issues on how to link the results of HTA to coverage.

That project was immediately followed by a European Commission-sponsored activity named HTA-Europe (from 1997 to 1998), which dealt with (i) emerging technologies, (ii) internationally coordinated assessments, (iii) measurement of outcomes in technology assessment, and (iv) the role of HTA in the future healthcare systems of the European countries (7).

In 2000, the European Commission supported a third major project in the field named The European Collaboration for Assessment of Health Interventions and Technology (ECHTA/ECAHI), which aimed at more specific collaboration for health technology assessment in Europe. All member states of the European Union and observers from eight other countries were involved in the project (approximately 110 medical and health policy experts in total).

In 2005, the Commission co-founded yet another huge HTA project at the European level, which defined itself to be a practical project to make European Collaboration sustainable and built on earlier results to achieve several objectives described below; the EUnetHTA project involving approximately 300 people from essentially all European countries.

\section{THE EUR-ASSESS PROJECT}

In 1992, the Netherlands, Sweden, France, the UK, and Switzerland, in particular, joined together to seek funding for a coordination program for HTA at the European level. After an unsuccessful proposal in 1992, it was funded in 1993 with David Banta as a leader.

The oversight of the project was carried out by a Steering Committee representing the major partners in the project, representing especially the countries mentioned in the previous paragraph.

The European Commission had made it clear that it would not support a coordination mechanism per se. It was, therefore, necessary to have substantive tasks. The key people working on the proposal decided to focus on four issues of importance to HTA: priority-setting, methods of HTA, dissemination and implementation of HTA, and health insurance coverage and HTA (a particular interest of the Swiss partners).

The project was essentially carried out in four subgroups on those four topics working relatively autonomously. The chairs of the groups were, in particular, those who had supported the attempt to gain support for the project. Others interested in the topics, and in some cases, experts in them as well, were invited to join the groups. A steering committee that met periodically reviewed progress and made suggestions. The reports for the subgroups were written by each subgroup. An overall synthesis was written by the coordinator of the project.

The reports themselves were interesting and useful. However, all participants believed that the more important outcome of the project was that people from several disciplines and nationalities worked closely together successfully for several years, and the results reflected the diversity of HTA approaches in Europe. With the passage of time, others involved in HTA in Europe identified themselves and were invited to attend Steering Committee meetings. By the end of the project in 1997, essentially all member states of the European Union were involved in the project, as well as others from other European countries. Another interesting outcome was the apparent stimulation of HTA activities in European countries. For example, in 1993, the project coordinator was unable to find an appropriate partner in Germany. By the end of the project, Germany had a representative from a public agency at the federal level and Germany established a national agency within the next few years.

The Steering Committee for the EUR-ASSESS project made several recommendations at the end of the project: (i) The European Commission should make funds available to support activities aimed at fostering communication on HTA between different countries, including conferences and meetings; (ii) The European Commission should support activities aimed at the development of robust and reliable systems for sharing information on HTA in Europe; and (iii) The European Commission should devote resources to studying the relationships between HTA and health systems in the member states of the European Union.

The Steering Committee also recommended to member states that "each country should have at least an organization 
(or a coordinating body) that can serve as contact point for technology assessment activities, including priority setting, dissemination, and implementation" (2).

\section{THE HTA EUROPE PROJECT}

The EUR-ASSESS project was followed by the HTA Europe project, also funded by the European Commission and led by David Banta. The main aim of the HTA Europe project was to develop papers on HTA and the health systems of all members of the European Union. Papers were commissioned from all countries to follow a common format. The papers were published in the international HTA journal (1).

The structure of the project was similar to that of the EUR-ASSESS project. However, the Steering Committee now represented all the member states of the European Union. Therefore, a significant accomplishment of the EURASSESS project was to identify experts or potential experts in HTA in different European countries and to bring them into the community of HTA workers in Europe.

Aside from the country papers, several workshops on strategic subjects were held.

At the end of the project, staff of the European Commission invited the coordinators of the project to produce a document developing the case for better coordination of HTA in Europe. The Commission decided to publish the resulting report as a policy document.

The main recommendation of the Steering Committee of the HTA Europe project was "It would be beneficial for the health care system of European Union countries for the European Commission to assist the establishment of a coordinating mechanism for HTA at the European level."

\section{THE ECHTA/ECAHI PROJECT}

The ECHTA/ECAHI project was funded by the European Commission for the period 1997-1999 and led by Egon Jonsson. The project was done in a similar way to the previous European projects, with a Steering Committee representing all member states and a series of six subgroups to consider the following topics: (i) assess health promotion and disease prevention activities in terms of benefits, risks, and economic, social, and ethical implications as a complement to community health indicators; (ii) develop systems for routine exchange of information between programs on emerging technology issues, priorities for future evaluation, and performance and timing of ongoing evaluations including findings from evaluations; (iii) identify possible joint assessments and to coordinate findings and existing resources within the community to support joint assessments; (iv) develop and disseminate best practices in undertaking and reporting assessments, and identify needs for methodological development; (v) develop and coordinate education and support networks for individuals and organizations undertaking or using assessment of health interventions and to identify needs in the field and assist in the establishment of new provisions; (vi) identify and share successful approaches that link findings of assessments to health policy and practice, and that contribute to health indicators and healthcare decision making.

A Steering Committee representing all member states guided the project, and an Executive Committee was responsible for system design and integration. A key challenge for the working groups was to take full advantage of relevant expertise within Europe.

The main goal of the project was to promote European cooperation, evidence-based health care in the European Community, and to explore opportunities to strengthen the network throughout the member states. The Steering Committee concluded the following:

There is now a need to strengthen this collaboration and create a sustainable Network within the European Union. The objective of the Network would be to assist the European Union, its member states and the candidate countries to plan, deliver and monitor health services effectively. Strong commitment and funding from the Commission would allow such a Network to achieve this objective. The Network should involve those working actively on assessments in health care in Europe, focusing on those in the public sector, but welcoming those working in other settings. The Network should be based on an agreed work plan, developed within the ECHTA/ECAHI project. A Steering Committee should oversee the Network, which should be supported by a Secretariat, initially placed in an existing HTA agency in a member state. The Network should work closely with global efforts of collaboration in the area, such as with INAHTA.

The full reports were published in IJTAHC. (11).

\section{THE EUnetHTA PROJECT}

The EUnetHTA project was established in response to a need for a sustainable European Network for HTA expressed in 2004 by the European Union and Member States. It was cofunded by the European Commission and participating partner organizations during the period of 2005-2008. The strategic objectives of the EUnetHTA Project were to reduce duplication of effort and promote effective use of resources for HTA, increase HTA input to decision making in Member States and the European Union to increase the impact of HTA, strengthen the link between HTA and healthcare policy making in the European Union and its member states, and support countries with limited experience with HTA (13). The project wanted to build on the results of the previous European projects and make their principles and methods more practical. That aim seems to have been achieved. (Details of the EUnetHTA and its products can be found on the Web site of EUnetHTA [www.eunethta.net].)

The project, led by Finn Boerlum Kristensen, involved essentially all institutions that had been involved in the earlier European projects. The initiative to respond to the call 
for a network came from the Danish and Finnish HTA agencies. The leaders in the earlier projects had mostly moved on to other activities and were no longer associated with the HTA institutions that they had represented in the 1990s. However, a major change was the number of institutions and individuals involved. By its end, the EUR-ASSESS project had almost 100 individuals involved. In contrast, the EUnetHTA project involved sixty-four organisations: one main partner (DACEHTA in Denmark), thirty-four associated partners, and twenty-nine so-called collaborating partners. In total, thirty-three countries (Europe: twenty-five European Union and two European Economic Area countries [Norway, Iceland], Switzerland and Serbia; outside Europe: Australia, Canada, Israel, United States) participated in the project. More than 300 individuals were directly involved in the project, including several from the new members of the European Union.

The main aim of those involved in the project was the development of practical tools for transnational collaboration and that a permanent coordination and communication for HTA would be set up at the conclusion of the project, funded by the European Commission. At a conference held in Paris on November 20, 2008, to present the work of the EUnetHTA project, a representative of the European Commission stated that HTA was a high priority for Europe and for the European Commission. However, he outlined the necessary steps before a permanent conclusion could be considered, ending with a statement that further funding could not be considered before 2010 (7). The leader of the project, Finn Borlum Kristensen, announced that twenty-five partners in the project had committed themselves to found a permanent EUnetHTA collaboration and to provide interim funding to keep EUnetHTA alive during 2009 (12).

After 15 years with noncontinuous and temporary funding from the European Commission for these activities, ample demonstration of the commitment and products of the partnership, and the repeated statements from the European Commission concerning the importance of HTA for Europe and its people, this outcome was so far disappointing. However, the Workplan for 2009 of the European Union Health Strategy 2008-13 called for a Joint Action on HTA between Member States and the Commission. Thus, the European Commission and the national HTA appointed bodies and representatives of Member States in February 2009 asked EUnetHTA to develop a proposal for a Joint Action to start by January 2010 .

\section{THE PRESENT SITUATION WITH HTA AGENCIES IN EUROPE}

By 2008, fourteen members of the European Union had formal HTA agencies. Most of those are represented by countries in this set of papers in this Supplement. The situation of the remaining countries, in brief, is as follows:
The Belgian Parliament established the Belgian Federal Health Care Knowledge Center by law late in 2002. The Center began to function in 2003. The Center has four research areas to cover, one of which is HTA. The Center is independent, but most of its studies are commissioned by the Ministry of Health. The Center joined INAHTA in 2004.

In Ireland, the Health Information and Quality Authority was established in May 2007. The organization is an independent authority funded by the Ministry of Health and reporting to the Minister of Health. The Authority has several tasks related to quality and functioning of the health services, one of which is HTA. The Authority is expected to assess the efficacy and cost-effectiveness of medicines, medical devices, diagnostics, and health promotion activities. The Irish government has been involved in all the European coordinating activities discussed above.

Latvia established a Health Statistics and Medical Technology Agency in 1998. In 1999, Banta heard rumors of the Agency, including that the definition of "technology" being used was confined to equipment. He visited the Center in 1999, and focused on the international development of HTA, and especially on the wide definition of health technology used. Jonsson, who had been a consultant on several missions of the World Bank in Latvia, also proposed that the Center ought to be responsible for HTA in the country. Subsequently, the World Bank funded a consultation aimed at strengthening the base of HTA in Latvia. Egon Jonsson and David Banta took on the role of strengthening the capacity for HTA in the country, ran a series of seminars on HTA in Latvia, including representatives of the Ministry of Health, and organized an extensive training program for the staff of the Center at SBU in Sweden. Furthermore, a consensus development conference on back pain was held in Latvia in 2002 (6) and one of the senior staff at the Center went through the Ulysses Program in HTA (www.ulyssesprogram.net/). The Center started to become very active with the international community and became a member of INAHTA, however, is still struggling with few resources to become a true national agency for HTA.

The European countries of Norway and Switzerland, not members of the European Union, also have HTA agencies, described by papers in this issue. The remaining countries in Europe, more than thirty of them, have no formal HTA agency. However, in several cases, there has been substantial activity in HTA. In Greece, for example, a law was passed to establish an HTA agency, but the development of the agency did not occur, apparently because of professional conflicts concerning who would lead the agency.

Serbia is a potential European Union candidate country. The World Bank has funded two large efforts aimed at establishing an HTA agency in Serbia. Plans are being made, but the agency has not yet been established.

Several of the remaining countries have shown interest in HTA without moving to establish HTA agencies. In 
Russia, the World Bank has promoted HTA activities and there is now a group of experts in HTA and evidence-based medicine, but there is little or no government activity in HTA. In Latvia, the World Bank along with the Swedish International Development Agency provided funding. Other countries that have shown some interest in HTA include all present members of the European Union, Turkey, and Albania.

On the other hand, some European countries, especially those in Eastern Europe have not been involved in HTA at all, as far as is known. Some examples, all from Eastern Europe, include Armenia, Azerbaijan, Belarus, Georgia, Kazakhstan, Moldova, and Ukraine.

\section{DISCUSSION}

HTA has spread widely in Western Europe, but has not yet penetrated to all European countries. One might say that the closer a country is to the European Union, either in spirit or in geography, the more likely it is to have a formal HTA program. However, it is probably equally true to say that every country that reaches a certain level of economic development moves to strengthen its health services, which seems to take it into HTA activities almost automatically.

Strong countries in HTA include, at least, Sweden, Norway, Finland, Denmark, the UK, Germany, France, Spain, Belgium, and the Netherlands. The story of HTA in Europe is essentially the continued spread of the ideas of HTA and of the establishment of formal activities and agencies. In several countries, HTA is seen as an essential tool for the planning and implementation of health policy in general and, specifically, of the location and use of health technologies to improve the health of the European population.

\section{CONTACT INFORMATION}

David Banta, MD, MPH (HD.Banta@ orange.fr), 9 route de Bragelogne, 10210 Villiers-le-Bois, France

Finn Børlum Kristensen, MD, PhD (fbk@ sst.dk), Director, DACEHTA, Adjunct Professor, National Board of Health, Islands Brygge 67, 2300 Copenhagen, Denmark

Egon Jonsson, PhD (ejonsson@ihe.ca), Professor, University of Alberta, and University of Calgary, Editor-in-Chief, International Journal of Technology Assessment in Health Care, Executive Director \& CEO, Institute of Health Economics, \#1200, 10405 Jasper Avenue, Edmonton, Alberta T5J 3N4, Canada

\section{REFERENCES}

1. Banta HD, Oortwijn W. Health technology assessment in the European Union. Int J Technol Assess Health Care. 2000;16:626-635.

2. Banta HD. Introduction to the EUR-ASSESS report. Int J Technol Assess Health Care. 1997;13:133-143.

3. Banta HD; European Advisory Committee on Health Research, World Health Organization Regional Office for Europe. Considerations in defining evidence for public health: The European Advisory Committee on Health Research World Health Organization Regional Office for Europe. Int J Technol Assess Health Care. 2003;19:559-572.

4. Banta HD, Geilijns A. Anticipating and assessing health care technology, vol. 1. General considerations and policy conclusions. Dordrecht: Nijhoff Publishers; 1987. Anticipating and assessing health care technology. vol. 2. India: Scenario Commission on Future Health Care; 2007.

5. Commission to the Council, The European Parliament, The Economic and Social Committee, and the Committee of the Regions on the Health Strategy of the European Community. Proposal for a decision of the European Parliament and of the Council adopting a program of community action in the field of public health (2001-2006). Brussels: Commission of the European Communities; 2000.

6. Consensus statement of Latvian consensus conference: Diagnosis and treatment of back pain. Int J Technol Assess Health Care. 2003;19:585-588.

7. Delogu B. DG SANCO views on future developments for EU collaboration on HTA. Presented at the conference HTA's Future in Europe, Paris, 20 November 2008. http:// www.eunethta.net/upload/Paris_Conference/PPTs\%20Final/17 _DeloguB_HTA_Paris_20_11_08.pdf. Accessed May 1, 2009.

8. Drummond MF, ed. Economic appraisal of health technology in the European Community. Oxford: Oxford University Press; 1987:103-118.

9. International Workshop on Evaluation of Medical Technology. Swedish Planning and Rationalisation Institute of the Health Services. SPRI. 1979;3089:1.

10. Jonsson E, Development of health technology assessment in Europe. Int J Technol Assess Health Care. 2002;18:171-183.

11. Jonsson E, Banta HD, Henshall C, Sampietro-Colom L. European collaboration for health technology assessment: Developing an assessment network. Int J Technol Assess Health Care. 2002; 18:213-455.

12. Kristensen FB. The EUnetHTA collaboration - way forward for HTA in Europe. Presented at the conference HTA's Future in Europe, Paris, 20 November 2008. http:// www.eunethta.net/upload/Paris_Conference/PPTs\%20Final/16 _Kristensen_afternoon_Paris_20_11_208.pdf. Accessed May $1,2009$.

13. Kristensen FB. EUnetHTA and health policy-making in Europe. Eurohealth. 2006;12:36-38.

14. Stocking B. News items. EEC: Medical technology assessment. Int J Technol Assess Health Care. 1987;3:623-628. 